Uluslararası Mühendislik

Cilt/Volume:11 Sayı/Issue:2 Haziran/June 2019

\title{
An Experimental Study To Determine Sliding Shear Strength And Internal Friction Coefficient Of Clay Brick Wall In A Masonry Building
}

\author{
Orhan Doğan 1 iD, Orhan Gazi Odacıŏglu 1 iD \\ ${ }^{1}$ Department of Civil Engineering Faculty of Engineering Kırıkale University, 71451, Kırıkkale, TURKIYE
}

\begin{abstract}
$96 \%$ of the available buildings in use in Turkey are taking place in the earthquake zone and approximately 50\% of them an masonry structures built using bricks. Sliding shear strength and internal friction coefficient were taken as a constant value in Turkish Earthquake Code (TSC 2007) depending on the type and hole rate of the brick section regardless of available compressive strength of the brick, mortar and plaster of a wall. But nowadays these values are recommended to be taken according to the compressive strength of mortar in TSC-2018. In addition, with this study it is recommended that, to evaluate the performance of a building against earthquake, the mechanical properties of the materials used for a building must be determined on site with series of tests. It is well-known that for each building mechanical properties of mortar and plaster are variable because of site work conditions.
\end{abstract}

In this study, a couple of tests were conducted in different storeys of a five-storey-masonry building representing the clay brick masonry buildings in the country built in the 1950s, to determine the sliding shear strength and internal friction coefficient, using a similar method to shove test. With the increment of axially vertical load from upper storey to lower storey, the shear capacity in the lower storeys of the buidling are much lower than the respective values in upper storeys. In order to determine a characteristic shear force for the building, it has been revised considering the lowest compressive strength of mortar in the storeys. Related with the internal friction coefficient obtained, a quite good correlation was found between the results and the standards. However, the sliding shear strength was found to be approximately three times higher than TSC 2007 and about two times higher than TSC 2018. This means that, the limits recommended in the standards are much safer than results obtained from the tests.

Key Words

"Masonry Building, Sliding Shear Strength, Risk Analysis of Masonry Buildings, Clay Bricks, Internal Friction Coefficient, Shove Test" 


\section{Inroduction}

The masonry structures are the combination of different types of wall materials like stone, brick, adobe bims-block with a lower strength and more flexible bonding mortar and plaster in comparison to the wall materials. In Tukey, which has seen a major earthquake about in every 30 years, it is of great importance to ensure the structural safety of the masonry structures.

Before the steel and reinforced concrete structures became widespread, masonry brick was generally used to build up low-storey buildings in Turkey. However, even though the block brick made of clay is produced at the same dimensions (Dalkıliç \& Nabikoğlu,2017), in the same mixing ratio and in the same section, the pressure strengths of bricks vary depending on the degree of heat treatment (Cultrone et al., 2004) and types of furnace (Bayülke N., 2013; Lourenço P.B. et al., 2010). Similarly the mortar and plaster have also different strengths depending on different rates of mixture (sand-cement-lime-water) (Haach et al., 2010) because of the master factor, different weather conditions (Berhane Z., 1984), different shapes, granule and pollution ratio of the sand and also different environmental effects (Almusallam A., 2001) of construction site. Because of these reasons, the shear and compressive strengths of bricks, mortar and plaster can vary from building to building and even in different storeys of a building.

Shear strength resisting the lateral earthquake force stems from the bond called sliding shear strength and residual frictional force that develops after the failure of the bond at the interface of brick and mortar. Different experimental models and methods are used to determine the sliding shear strength and frictional force between mortar and brick such as shove (Ispir M. et al., 2010; Ferretti F. et al., 2019), Nuss, triplet, core (Rahman A. \& Ueda T., 2013), Van der Pluijm (Pluijm R., 1992) etc. Shove test is an in-situ test to determine the sliding shear strength and frictional force of a brick wall making a brick slid in mortar. According to Colulomb's law, the sliding shear stress in the standards is variable according to the compressive strength of the mortar or the type and hole ratio of the brick, but the internal friction coefficient is constant. The standard EN 1052-3 triplet laboratory test in Europe may result in significant differences according to the laboratory-simulated in-situ tests (Bonura V. et al., 2018; Andreotti G. et al., 2018).

Performance analysis of the existing buildings including monumental buildings (Ozturk B., 2008; Ozturk B., 2017) against earthquake and their renovation or strengthenings are encouraged and even imposed by the Turkish Government in recent years. According to the Turkish codes (TSC 2018; TSC 2007), the performance of an existing masonry building against earthquake is evaluated only according to the sliding shear performance of its walls.

The aim of this study is to investigate the sliding shear strength and friction coefficient of a wall in an existing masonry building, depending on the variable exposed wall loads and the strength of the plaster and mortar, varying in different floors of the building, instead of taking these parameters constant for a building as indicated in the TSC-2018 Code.

\section{Materials and Testing Method}

\subsection{Structural Properties}

The building (with ground floor 19,50x11 meters in size, each floor 3 meters in height, 14 and $27 \mathrm{~cm}$ wall thicknesses and $12 \mathrm{~cm}$ floor slab thicknesses), chosen in this study as a sample for the tests, had been primarily constructed as a 4-storey residence with clay block brick in Ankara built in 1950's, province as shown in Figure 1. But later on, in 1955 an additional $5^{\text {th }}$ floor was built using vertical perforated brick with less than $35 \%$ hole ratio. It is seen that two types of clay bricks in the same sizes of $215 \times 102 \times 65 \mathrm{~mm}$ were used for the building in which total wall thickness is about $27 \mathrm{~cm}$, plaster thicknesses on two sides of the wall are $3-3.5 \mathrm{~cm}$ in total and bed joint and head joint mortar thickness is $1.5-2 \mathrm{~cm}$ between bricks.
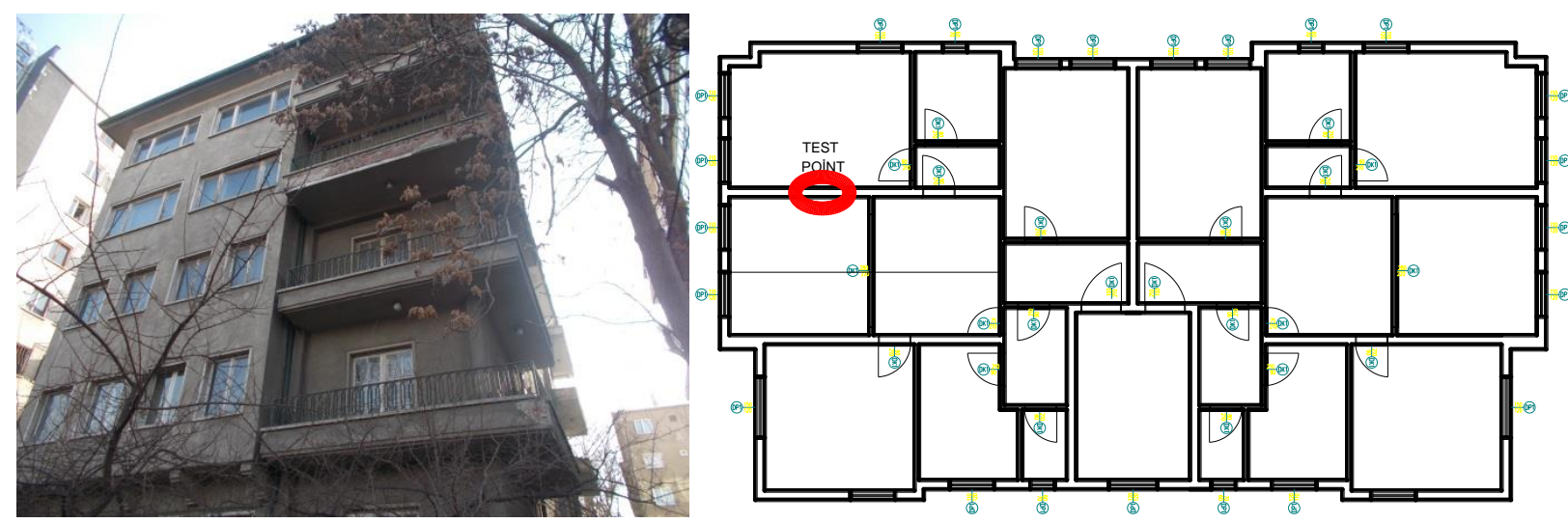

Figure 1: Front facade of the building and storey plan

\subsection{Preparation of Test Specimens and Instrumentations}

The specimens prepared on the $2^{\text {nd }}, 3^{\text {rd }}$ and $5^{\text {th }}$ storeys are 3 rows of bricks in height and 1.5 bricks in length. The specimen prepared on the $4^{\text {th }}$ storey is 3 rows of bricks in height and 2 bricks in length as given Table 1 . Taking bricks out of the wall, two limited gaps formed on the both sides of the specimens, to set up the hydraulic jack in one and the dial gage to the other gap. It is 
aimed to investigate sliding shear performance in mortars taking place on the top and bottom of the specimen, applying quasistatic lateral load from one side of the specimen with hydraulic-jack and measuring lateral displacement from other side of the specimen with dial-gage. The deformed surface of the specimen taking place on the loading side is filled with repair mortar smoothly to apply the lateral distributed load uniformly without damaging the existing plaster taking place on both surfaces of the wall.

Table 1. Sizes of the specimens for each storey

\begin{tabular}{llllllll}
\hline Storey & Type of brick & $\begin{array}{l}\text { Width } \\
(\mathbf{c m})\end{array}$ & $\begin{array}{l}\text { Height } \\
(\mathbf{c m})\end{array}$ & $\begin{array}{l}\text { Thickness } \\
\text { of wall }(\mathbf{c m})\end{array}$ & $\begin{array}{l}\text { Thickness } \\
\text { of mortar } \\
(\mathbf{c m})\end{array}$ & $\begin{array}{l}\text { Thickness } \\
\text { of plaster } \\
(\mathbf{c m})\end{array}$ & $\begin{array}{l}\text { Total } \\
\text { thickness } \\
(\mathbf{c m})\end{array}$ \\
\hline 2 & Clay Brick & 35 & 24 & 22 & 2 & $2-3$ & 27 \\
3 & Clay Brick & 34 & 26 & 22 & $1.5-2$ & $2-3$ & 27 \\
4 & Clay Brick & 48 & 23 & 22 & 2 & $2-3$ & 27 \\
5 & Hollow Clay Brick & 36.5 & 24 & 22 & 2 & $2-3$ & 27 \\
\hline
\end{tabular}

\subsection{Testing Method}

In order to determine in situ shear strength of masonry walls, specimens were prepared according to the Method B given in ASTM C 1531-03 as shown in Figure 2. In Method B only one brick is prepared as a specimen but in the this study more than one brick is prepared to avoid deformation of small specimen during preparation and to investigate size effect. Specimens were prepared on the same axis and in the same locations but on different floors.

The quasi-static load was applied laterally with a hydraulic jack and a pump unit and the lateral displacement of the test unit was measured using a dial-gage. During the tests the lateral cracks in the top and the bottom bed joint mortar was occurred. The test was carried out until reaching residual sliding shear which is approximately $10 \%$ of maximum load. The failure of the specimen is primarily occurred in plaster then occurred in mortar bond in the upper and lower sides of the specimen.

(a)

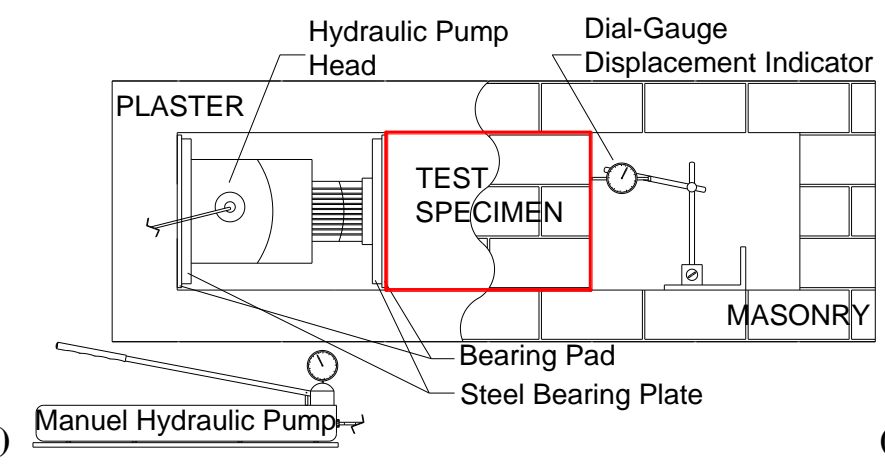

(b)

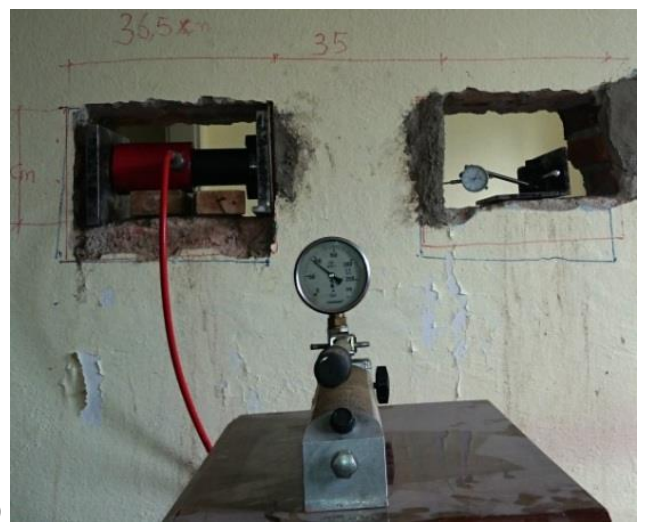

Figure 2: (a) Testing model design and instrumentation (b)Test model and loading system

\section{Analysis Of The Test Results}

\subsection{Analysis of axial compression load acting on the test specimen}

Herein as indicated the Method B of ASTM C 1531-03 Code, the vertical axial force caused by the building's own weight acting on the test specimens, were calculated for each specimen on different storeys as shown in the Figure 2.(a). The load distribution on the wall and the particular load acting on the specimen and the vertical section of the wall are shown in Figure 3.
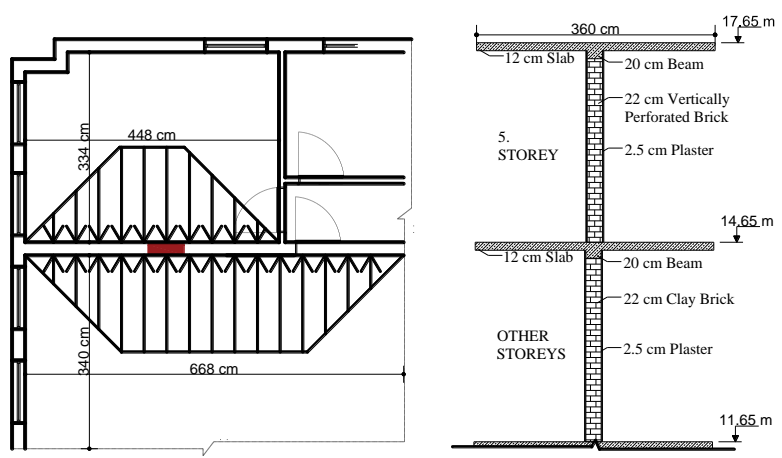

Figure 3. Load distribution acting on the wall and the specimen and the vertical section of the wall 
A simplistic comparison of the parameters determined through laboratory shove tests with those obtained via triplet tests may result in significant differences as a result of the wrong estimation of the compressive stress acting on the mortar joints $\left(\sigma_{\mathrm{j}}\right)$ in the shove test (Andreotti G. et al., 2018). That is why to ensure about the compressive stress acting on the mortar joints $\left(\sigma_{\mathrm{j}}\right)$ in the shove test, the compressive stress acting on the specimen is calculated mathematically using structural geometry and compared with the results of 3D (StatiCAD) structural analysis program and quite good correlation obtained between these two results.

The vertical load applied on the wall and the specimen was calculated according to the TS 771-1 code. The density of the wall with plaster, the reinforced concrete, the ceiling plaster, the floor leveling concrete and weight of the roof covering in square meter are recommended as $1800 \mathrm{~kg} / \mathrm{m}^{3}, 2400 \mathrm{~kg} / \mathrm{m}^{3}, 2000 \mathrm{~kg} / \mathrm{m}^{3}, 2000 \mathrm{~kg} / \mathrm{m}^{3}$ and $150 \mathrm{~kg} / \mathrm{m}^{2}$ respectively in the TSC $2007 \mathrm{and}$ TS 498 codes.

The wall height and thickness (including plaster), the thickness of the mortar and plaster mortar and the dimensions of the bricks were measured.

\subsection{Analysis of shear strength}

It has been observed that the ultimate shear forces $\left(\tau_{\mathrm{u}}\right)$ varied between 101 and $197 \mathrm{kN}$. The main reasons of this variation in shear load capacity are the higher sizes of the specimen and the higher strength of the mortar on the fourth floor in comparison to the other floors. The specimens showed a rapid loss of shear stress after reaching at the ultimate shear forces varying between 101.1 and $196.7 \mathrm{kN}$ and the optimum displacement varying between 2.56 and $4.20 \mathrm{~mm}$ as shown in Figure 4 . and Table 2.

Table 2. Shear force and displacements of the specimen

\begin{tabular}{lllll}
\hline Storey & \multicolumn{1}{c}{$\mathbf{T}_{\mathbf{u}}$} & \multicolumn{1}{c}{$\Delta_{\mathbf{u}}$} & \multicolumn{1}{c}{$\mathbf{T}_{\mathbf{r}}$} & $\begin{array}{c}\Delta_{\mathbf{r}} \\
\mathbf{m m}\end{array}$ \\
\hline 2 & $\mathbf{k N}$ & $\mathbf{k N}$ & $\mathbf{k N}$ & 46.41 \\
3 & 125.5 & 2.56 & 12.0 & 45.70 \\
4 & 112.0 & 4.20 & 12.4 & 40.03 \\
5 & 196.7 & 3.40 & 63.7 & 46.85 \\
\hline
\end{tabular}

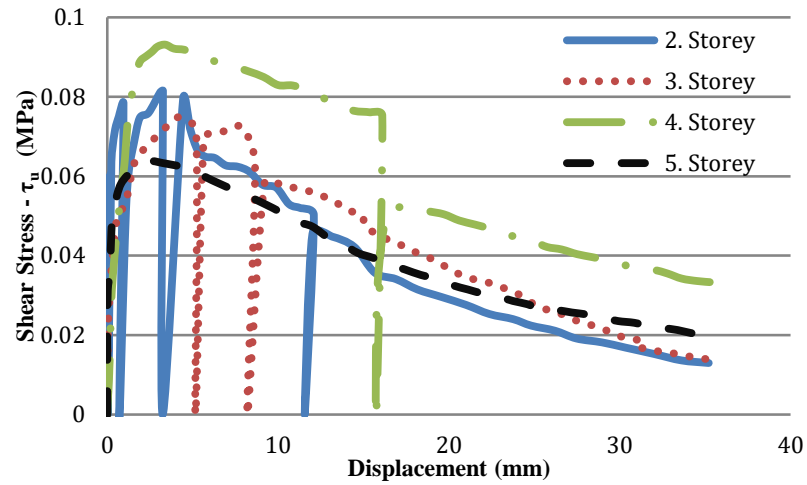

Figure 4. Shear stress and displacement

The ultimate shear stress $\left(\tau_{\mathrm{u}}\right)$ and residual shear stress $\tau_{\mathrm{r}}$ were calculated by dividing the acted lateral shear force $(\tau)$ on the specimen with the total top and bottom shear areas (A) of the specimen. The correlations between the ultimate shear and compression stresses are given in the equation 1, in Table 3 and in Figure 5 (a).

After reaching the ultimate shear strength, the tests were carried out until a residual frictional force was attained. It was found that the ratio of the residual frictional force to the ultimate shear force was obtained as $1 / 10$ for the block bricks and as $1 / 5$ for the perforated bricks. During the test on the second floor, the specimen behaved as an elasto-plastic material before reaching ultimate strength. After the ultimate strength, it was unloaded and loaded. It behaved completely plastic after the unloading process without adherence crack as shown in Figure 4.

\subsection{Reconsideration of sliding shear stress using hammer rebound reading of the mortar}

$\mathrm{N}$-Schmidt hammer test was used as a non-destructive and quick test method, to determined compressive strength of brick, mortar and plaster. A big difference was observed in compressive strength of brick, mortar and plaster in different floors in the hammer readings. Therefore instead of taking constant mechanical properties for all masonry buildings, the variation of mechanical properties of wall materials and the quality of the construction was taken care during reconsideration of sliding shear stress. It was determined that while the mortar and plaster results giving very close readings to each other, the general average readings of the mortar and plaster were 50\% less than the average reading of the brick. So the most effective parameter in determination of the wall shear performance is the determination of mortar and plaster strength as the weakest chain of the wall. Therefore N-Schmidt reading of the mortar and plaster can have a priority in the determination of the wall shear performance as the most practical method. To evaluate sliding shear stresses all together, these differences between the results were reconsidered using only for hammer rebound readings of the mortar instead of brick.

Average rebound reading of the fourth floor mortar was quite higher than the other floor mortars. Because of the higher rebound reading and shear stress of mortar on the fourth floor, the regression $\mathrm{R}^{2}$ of the Equation- 1 was 0.13 . To eliminate this uncertainty in regression analysis, ultimate shear strengths were revised by dividing the ultimate shear stresses to the ratios which is calculated by dividing the different floor rebound readings to the lowest rebound reading of third floor. The regression analysis of revised shear values $\left(\tau_{\mathrm{ur}}\right)$ is more meaningful and compatible with the regression $\mathrm{R}^{2}$ of the Equation- 2 was 0.89 . Non-revised and revised shear values and graphics are given in Table 3 and Figure 5 (a). 


$$
\begin{gathered}
\tau_{u}=0.58+0.24 \sigma_{n} \\
\tau_{u r}=0.45+0.42 \sigma_{n}
\end{gathered}
$$

Table 3. N-Schmidt hummer test rebound readings for brick, mortar and plaster and the axial stresses, non-revised and revised

\begin{tabular}{|c|c|c|c|c|c|c|c|c|c|c|}
\hline \multirow[b]{2}{*}{ Storey } & \multicolumn{3}{|c|}{ N-Schmidt hummer test rebound readings } & \multicolumn{7}{|c|}{ Strain and displacements } \\
\hline & Brick & Plaster & Mortar & $\begin{array}{c}\sigma_{\mathrm{n}} \\
\mathrm{MPa}\end{array}$ & $\begin{array}{c}\tau_{\mathbf{u}} \\
\mathrm{MPa}\end{array}$ & $\begin{array}{c}\tau_{\mathrm{r}} \\
\mathrm{MPa}\end{array}$ & Ratios & $\begin{array}{c}\tau_{\mathrm{ur}} \\
\mathrm{MPa}\end{array}$ & $\begin{array}{c}\Delta_{\mathbf{u}} \\
\mathbf{m m}\end{array}$ & $\begin{array}{r}\Delta_{\mathbf{r}} \\
\mathbf{m m}\end{array}$ \\
\hline 2 & 26.50 & 19.50 & 12.00 & 0.44 & 0.66 & 0.06 & 1.09 & 0.61 & 2.56 & 46.41 \\
\hline 3 & 32.50 & 15.25 & 11.00 & 0.32 & 0.61 & 0.07 & 1.00 & 0.61 & 4.20 & 45.70 \\
\hline 4 & 28.50 & 15.00 & 16.00 & 0.20 & 0.76 & 0.25 & 1.45 & 0.52 & 3.40 & 40.03 \\
\hline 5 & 49.75 & 12.50 & 12.00 & 0.09 & 0.52 & 0.12 & 1.09 & 0.48 & 2.55 & 46.85 \\
\hline Average & 34.31 & 15.57 & 13.25 & & & & & & & \\
\hline
\end{tabular}
shear stresses acting on the specimens and lateral displacements

The sliding shear strength and friction coefficient between the brick and the mortar interface of the masonry walls are found different from the individual codes as seen in Table 4 and Figure 5 (b). The ASTM C1531-03 code indicates that the friction coefficient varies in the range of 0.3-1.6 MPa while the sliding shear strength does not give a specific value for the cracking resistance. TSC 2018 code specifies that the sliding shear strength will be in the range of $0.2 \mathrm{MPa}$ depending on the range of 2-9 MPa compressive strength of the mortar, while the friction coefficient is 0.4 . While the TSC 2007 code does not consider the strength of the mortar, it accepts that the friction coefficient is only 0.5 and sliding shear strength varies depending on the type and sectional hole rate of the bricks. This study showed that the compressive strength of the mortar and even the plaster are the two most important parameters in determining sliding shear strength. Because the strength of the brick is higher than the strength of the mortar and plaster, TSC 2018 code recommends that sliding shear strength is based on only compressive strength of mortar. In addition, if the strength of the plaster is different from the mortar, the strength of the plaster should also be taken into consideration. In this study, the mortar and the plaster with $5 \mathrm{MPa}$ compression strength, gathered using hammer readings and evaluating according to the technical research of Szilágyi and Borosnyói (2009), gave about 0.45 MPa sliding shear strength and 0.42 friction coefficients.

\begin{tabular}{|c|c|c|c|}
\hline & Material properties & $\tau_{\mathbf{0}}$ & $\mu$ \\
\hline ASTM C 1531-03 & Block and perforated concrete and clay bricks & - & $0.3-1.6$ \\
\hline \multirow{3}{*}{$\begin{array}{c}\text { EN 1996-1-1 (2006) and } \\
\text { TSC (2018) }\end{array}$} & Mortar (M1-M2) & 0.10 & \\
\hline & Mortar (M2-M9) & 0.20 & 0.4 \\
\hline & Mortar (M10-M20) & 0.30 & \\
\hline TSC (2007) & Clay bricks & 0.15 & 0,5 \\
\hline Test results & Clay Block Bricks - Mortar (approximately $5 \mathrm{MPa}$ ) & 0.45 & 0.42 \\
\hline
\end{tabular}

Table 4. Shear stress and friction coefficient of codes and test results

(a)

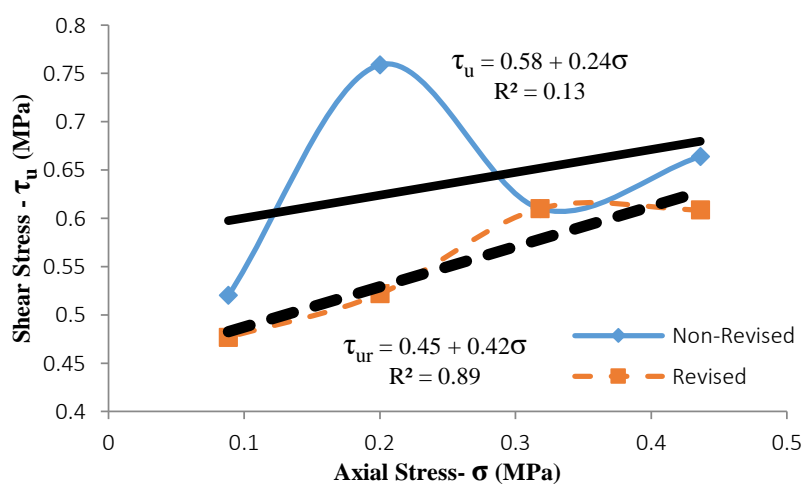

(b)

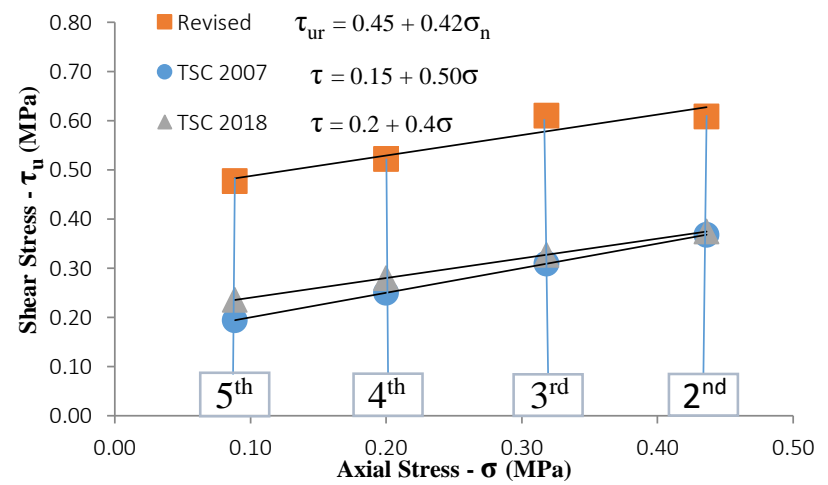

Figure 5. (a) Non-revised and revised shear and axial stress (b) Comparison of test results with the codes 


\section{Conclusions and suggestions}

In this study, it is understood that the mechanical properties of the masonry walls used mortar is variable for every building even every storey in a building because of the percentages of cement and lime components in mortar. Series of tests were conducted in different storeys of a five-storey masonry building built in the 1950s, to determine the sliding shear strength and internal friction coefficient, using a shove testing method similar to the one given in the ASTM C 1531-03 code.

Consequently;

- It is found that the ratio of the residual frictional strength to the ultimate shear strength is approximately $1 / 10$ for block bricks and $1 / 5$ for hollow brick. The residual frictional strength of vertical perforated bricks is two times more than the residual frictional strength of block bricks. Quasi-static tests showed that after reaching the ultimate shear strength, they behaved completely plastic.

- It is seen that to determine a single sliding shear strength for a masonry building analysis, it is a better to use experimentally determined shear strength of each storey, because mechanical properties of the mortar and plaster vary for each storey, instead of taking a constant value for all storeys.

- This study showed that the compressive strength of the mortar and even the plaster are the two most important parameters in determining sliding shear strength, since the strength of the brick is higher than the strength of the mortar and plaster. That is why in this study to investigate the sliding shear strength of masonry, only compressive strength of mortar and plaster is taken care.

- When this study carried out, TSC 2007 code was in valid and it was not considering the strength of the mortar and plaster, but it was accepting the friction coefficient is constant and the sliding shear strength varies depending on the type and sectional hole rate of the vertical perforated bricks, In the meantime ASTM C 1531-03 and TSC 2018 codes specify these values depending on only the mortar. In this study it is determined that the mortar and the plaster with about $5 \mathrm{MPa}$ compressive strength gave $0.45 \mathrm{MPa}$ sliding shear strength and 0.42 friction coefficients.

- The test results about internal friction coefficient were found quite compatible with the codes (ASTM C 1531-03, TSC 2018). However, the ultimate shear strength achieved for block bricks built with 5 MPa mortar, was found approximately three times more secure than TSC 2007 code and about two times more secure than TSC 2018.

- If the correlation can be proved, instead of using a destructive shove test method as recommended in ASTM C 1531-03 code, the N-Schmidt hammer test can be used as a non-destructive method which is more practical to determine the shear performance of the masonry buildings depending on the compressive strength of mortar and plaster.

\section{Referanslar}

Almusallam, A.A. (2001). Effect of environmental conditions on the properties of fresh and hardened concrete. Cement and Concrete Composites, 23(4-5), 353-361.

Andreotti, G., Graziotti, F., \& Magenes, G. (2018). Detailed micro-modelling of the direct shear tests of brick masonry specimens: the role of dilatancy. Engineering Structures, 168, 929-949.

ASTM C 1531-03 (2003). Standard Test Method for In Situ Measurement of Masonry Joint Shear Strength Index. West Conshohocken, United States.

Bayülke, N. (2003). Yı̆̆ma yapılar Taş ve Tuğla. IMO Yayınları. Ankara.

Berhane, Z. (1984). Evaporation of water from fresh mortar and concrete at different environmental conditions. In Journal proceedings, 81(6), 560-565.

Bonura, V., Jafari, S., Zapico Blanco, B., \& Graziotti, F. (2018). Interpretation of in situ shear test for brick masonry: a benchmark study. In Proceedings of the 16th European conference on earthquake engineering, 16ECEE. 18-21.

Cultrone, G., Sebastián, E., Elert, K., De la Torre, M. J., Cazalla, O., \& Rodriguez-Navarro, C. (2004). Influence of mineralogy and firing temperature on the porosity of bricks. Journal of the European Ceramic Society, 24(3), 547-564.

Dalkilic, N., \& Nabikoglu A. (2017). Traditional manufacturing of clay brick used in the historical buildings of Diyarbakir (Turkey). Frontiers of Architectural Research. 6(3). 346-359

EN 1996-1-1 (2006) Eurocode 6: Design of masonry structures-General rules for reinforced and unreinforced masonry structures. CEN, EU.

Ferretti, F., Ferracuti, B., Mazzotti, C., \& Savoia, M. (2019). Destructive and minor destructive tests on masonry buildings: Experimental results and comparison between shear failure criteria. Construction and Building Materials, 199, 12-29.

Haach, V. G., Vasconcelos, G., \& Lourenço, P. B. (2011). Influence of aggregates grading and water/cement ratio in workability and hardened properties of mortars. Construction and Building Materials, 25(6), 2980-2987. 
Ispir, M., Demir, C., Ilki, A., \& Kumbasar, N. (2009). Material characterization of the historical unreinforced masonry Akaretler row houses in Istanbul. Journal of Materials in Civil Engineering, 22(7), 702-713.

Lourenço, P. B., Fernandes, F. M., \& Castro, F. (2010). Handmade clay bricks: Chemical, physical and mechanical properties. International Journal of Architectural Heritage, 4(1), 38-58.

Ozturk, B. (2008). Investigation of seismic behavior of a monumental building in Historical Cappadocia Region of Turkey. In 14th world conference on earthquake engineering, Beijing, China.

Ozturk, B. (2017). Seismic behavior of two monumental buildings in historical Cappadocia region of Turkey. Bulletin of Earthquake Engineering, 15(7), 3103-3123.

Rahman, A., \& Ueda, T. (2013). Experimental investigation and numerical modeling of peak shear stress of brick masonry mortar joint under compression. Journal of Materials in Civil Engineering, 26(9), 1-12. doi.org/10.1061/(ASCE)MT.19435533.0000958

Szilágyi, K., \& Borosnyói, A. (2009). 50 years of experience with the Schmidt rebound hammer. Concrete Structures, vol 10, 4656.

TS 498 (1997) Yapı Elemanlarının Boyutlandırılmasında Alınacak Yüklerin Hesap Değerleri. Ankara, Turkey.

TS EN 12504-2 (2004) Testing concrete in structures, part-2 non-destructive testing, determination rebound number, Standard. Ankara, Turkey.

TS EN 771-1 (2005) Specification for Masonry Units-Part 1: Clay Masonry Units. Ankara, Turkey.

TSC (2007). Specification for buildings to be built in earthquake zones. Ministry of Public Work and Settlement, Ankara, Turkey

TSC (2018) Turkish Earthquake Code: Specifications for Building Design Under Earthquake Effects. Ministry of Public Work and Settlement, Ankara, Turkey

Van der Pluijm, R. (1992). Material properties of masonry and its components under tension and shear. In Proceedings 6th Canadian Masonry Symposium, 15-17 June 1992, Saskatoon, Canada. 675-686. University of Saskatchewan. 